Portland State University

PDXScholar

3-15-2021

\title{
Public Perception of Air Quality Risks in Portland, Oregon
}

\author{
Dawn Nolan \\ Portland State University
}

Follow this and additional works at: https://pdxscholar.library.pdx.edu/open_access_etds

Part of the Communication Commons, and the Environmental Health Commons Let us know how access to this document benefits you.

\section{Recommended Citation}

Nolan, Dawn, "Public Perception of Air Quality Risks in Portland, Oregon" (2021). Dissertations and Theses. Paper 5667.

https://doi.org/10.15760/etd.7539

This Thesis is brought to you for free and open access. It has been accepted for inclusion in Dissertations and Theses by an authorized administrator of PDXScholar. Please contact us if we can make this document more accessible: pdxscholar@pdx.edu. 
Public Perception of Air Quality Risks in Portland, Oregon

by

Dawn Nicole Nolan

A thesis submitted in partial fulfillment of the requirements for the degree of

\author{
Master of Science \\ in \\ Communication
}

Thesis Committee:

Brianne Suldovsky, Chair

Cynthia-Lou Coleman

Erin Spottswood

Portland State University

2021 
(C) 2021 Dawn Nicole Nolan 


\begin{abstract}
The availability and demand for localized air quality information from communities are on the rise. However, not all information and not all communities are the same. Effective engagement and communication strategies will depend on a community's existing knowledge, opinion about air quality, individual experiences with inequities, and more. This study aims to understand how people living in Portland, Oregon understand and experience air pollution as an environmental risk and examine the extent to which those risk perceptions relate to confidence in science and technology. This gap is critical because of the complex interaction between air pollution and the risk perception of increased advancements in science and technology.

Data were collected from early March through early April 2020 via an online survey administered through Qualtrics. The population of interest was respondents who live within the city limits of Portland, Oregon. The online survey measured a total of 1,000 Portlander's and their risk perceptions as defined by the EPPM (perceived severity, perceived susceptibility, and self-efficacy) and confidence in science and technology to solve environmental problems. Results found that confidence in science and technology is positively correlated with self-efficacy, and negatively correlated with perceived severity and susceptibility. In other words, it was found that higher confidence in science and technology is associated with feeling like one can protect themselves from air pollution and feeling like air pollution is not a severe risk that one is susceptible to. Conversely, perceptions of high severity and susceptibility are associated with lower
\end{abstract}


confidence in science and technology. Implications and opportunities for future research are discussed. 


\section{Table of Contents}

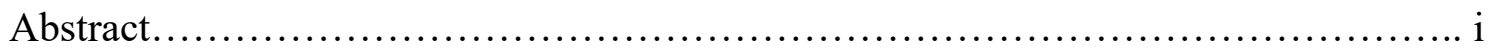

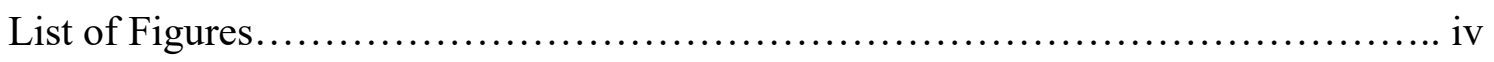

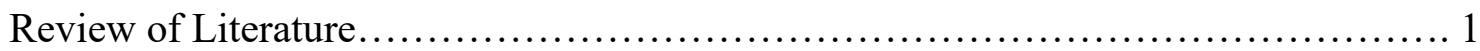

Methods................................................................ 17

Results.............................................................. 21

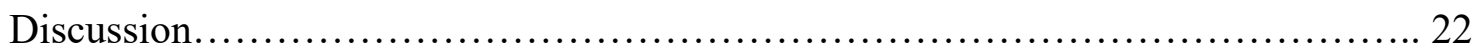

References......................................................... 32

Appendix A - Survey Protocol................................................. 43 


\section{List of Figures}

Figure 1.1 - Witte's 7 Extended Parallel Process Model (EPPM).................... 7 


\section{Review of Literature}

\section{Introduction}

Understanding public perception of air pollution is critical for successful public engagement, especially as scientific advancements surrounding detecting and mitigating air pollution continue to progress. Air pollution is one of the world's largest invisible killers and a significant environmental risk to individual and community health (Chengao, W.A.N.G, 2000; Fuller, 2018; O'Connor, 2019). It has no prejudice or motives and affects people in low, middle- and high-income countries (Makri, \& Stilianakis, 2008). Air pollution causes seven million premature deaths a year, making it the most substantial single environmental health risk, according to the World Health Organization (WHO, 2014). Ambient (outdoor) air pollution in both cities and rural areas is estimated to have caused 4.2 million premature deaths worldwide per year in 2016 (WHO, 2016). In a report released by WHO in 2012, around 7 million people died - one in eight of total global deaths - as a direct result of air pollution exposures. In addition to harming human health, air pollution can harm plants and animals, pollute waterways, and contributes to climate change (Brauer, Amann, Burnett, Cohen, Dentener, Ezzati \& Van Donkelaar, 2012).

Air pollution as an environmental risk is intimately tied to developments in science and technology. Scientific advancements in reducing air pollution have the potential to save millions of lives globally by reducing the burden of disease from stroke, heart disease, lung cancer, and both chronic and acute respiratory diseases such as asthma (Ngo, Bao \& Zhong, 2018; WHO, 2018). There are multiple examples of successful policies in transport, urban planning, power generation, and industry that reduce air 
pollution via technological advancements (WHO, 2018). When scientists encounter problems that they cannot solve by currently available technologies it creates a give and take between researchers and a shared creativity that drives the development and creation of more innovative avenues (Mao \& Vinson, 2018). These advancements offer some promise in reducing air pollution. For example, utilizing "gas to liquid" (GTL), Shell has developed a new synthetic fuel made from natural gas which is a "drop-in" replacement for diesel. The engines would require no modification and the overall cost is kept minimal (Howard, 2016). Yet another fuel modification can be found in utilizing hydrogen fuel additives. When small amounts of hydrogen are fed into the vehicle's air intake this, in turn, creates a more efficient burn. Technological advancements for combatting air pollution are constantly in motion and it will be a potential challenge for policymakers to remain supportive through research and progressive movement (Howard, 2016).

The current health risk of poor air quality and a simultaneous rise in technological advancements aimed toward improving air quality point to a need to better understand public opinion dynamics. When a country makes initial investments in basic production and physical framework, it often pays less attention to the detrimental effects of that investment on environmental quality. However, as developments progress the underlying structure of a country's economy shifts in ways that expand the size of the middle class. This expansion, in turn, has the potential to change community preferences and create attitudes favorable towards the improvement of environmental quality utilizing technology. Together these shifts may enable countries the opportunity to afford the purchase of advanced and cleaner technologies (Arrow, Bolin, Costanza, Dasgupta, 
Folke, Holling, Jansson, Levin, Maler, Perrings \& Pimentel, 1995). This study aims to recognize how people living in Portland, Oregon understand and experience air pollution as an environmental risk and examine the extent to which those risk perceptions relate to confidence in science and technology. This gap is critical because of the complex interaction between air pollution and the risk perception of increased advancements in science and technology.

\section{Current Study: Portland, Oregon}

This section discusses the health risk level of Portland, Oregon, and details out statistical evidence that elicits the importance of researching air pollution risk and public perception. According to the Environmental Protective Agencies National Air Toxics Assessment (2014), the state of Oregon has the third-largest population at risk of excess cancer due to air pollution in the United States. These troubling statistics are trailing only behind California and New York. Spanning the widespread communities in the state of Oregon, 117 schools fall in the worst $10 \%$ nationally for exposure to industrial pollution (NATA, 2014; Neighbors for Clean Air, 2018). In the past several years, air toxics have taken on a key role as air pollutants of extreme concern throughout the Portland, Oregon region. In 2019, the American Lung Association's "State of the Air" 2019 report found that the Portland metro area is currently the $23^{\text {rd }}$ most polluted area in the United States for short-term particle air pollution (Harvey, 2019).

Portland's air is, in fact, much "dirtier" and poorer quality than we initially thought. Another study conducted by researchers at the U.S. Forest Service revealed dangerously high levels of heavy metals in Portland (Baer, 2017). The detailed study of tree moss, in May 2015, in Southeast Portland neighborhoods, revealed high levels of 
arsenic, cadmium, nickel, and lead in the air surrounding a pair of Portland glass companies, Bullseye, and Uroboros Glass Studio. Moss, which is one of the world's oldest nonvascular spore-bearing land plants, is also highly in tune with the atmosphere and air pollution levels surrounding it (American Chemical Society, 2018). The Department of Environmental Quality (DEQ) tested tree trunks and branches at 346 sites throughout Portland. In locations surrounding the Bullseye plant, it was found that arsenic levels were 155 times higher than DEQ's acceptable range and cadmium was approximately 49 times higher (Gatziolis, Jovan, Donovan, Amacher \& Monleon, 2016). The revelation of the air pollution levels surrounding these communities being so high initiated an aggressive community campaign to clean up the toxic pollution. Risk perceptions are an important evaluation because they directly influence people's response to certain air pollution communication strategies. The level of perceived air pollution and health risk perception plays are very important in understanding risk.

\section{The Extended Parallel Process Model}

The Extended Parallel Process Model was first introduced in 1992 and has been actively utilized as a framework to address and understand various health and environmental risks (Murray-Johnson, Witte, Patel, Oorrego, Zuckerman, Maxfield \& Thimons, 2004; Witte, 1992, Witte, 1995). According to EPPM, two primary factors contribute to the acceptance of a persuasive or fear appeal message that can lead to either a danger control response or fear control response: Perceived efficacy (self-efficacy and response-efficacy) and perceived threat (susceptibility and severity) (Witte, 1992).

Perceived efficacy can be defined as an individual's beliefs about the effectiveness, feasibility, and ease with which a recommended response rings valid and 
their capabilities to produce designated levels of performance that create change over events that affect their everyday lives. There are two types of self-efficacy in EPPM; selfefficacy and response efficacy. Self-efficacy is the belief that an individual possesses the ability to follow through with the recommended response to avoid the threat or problem being addressed (Gore \& Bracken, 2005; Popova, 2012). For example, a student that possesses a high level of self-efficacy to engage in healthy behaviors is vital for student success. Increasing air pollution preventative behaviors is essential for future health effects as well as an individual's quality of life. Does the student feel that they can successfully avoid exercising outdoors when pollution levels are high? And if so, do they know how to check daily air pollution forecasts in their area? (American Lung Association). The second type of self-efficacy in EPPM is response efficacy, which can be defined as the belief regarding the effectiveness of the recommended response in avoiding the threat (Popova, 2012; Witte, Cameron, McKeon \& Berkowitz, 1996). When individuals believe that the recommended action will help them in avoiding the threat, they will respond favorably. For example, the belief that receiving the flu vaccine will indeed protect themselves from the flu during a potentially large outbreak is a favorable response.

Perceived threat is a subjective evaluation of risk (Bandura \& Walters, 1977). Per Witte (1996), there are two ways in which individuals evaluate a threat - perceived susceptibility and perceived severity. Perceived susceptibility is the belief regarding an individual's risk of actually experiencing the threat (Popova, 2012; Witte et al., 1996). For example, if an individual believes that their likelihood of experiencing a specific health risk is high, they will engage in behaviors that will reduce their chances of 
developing the feared health risk. The second dimension of perceived threat is perceived severity. Perceived severity can be defined as the belief regarding the significance or magnitude of the threat, beliefs concerning the consequences of compliance or not complying regarding a specific event (Popova, 2012; Witte et al., 1996). When an individual perceives the severity of environmental risk or health risks are severe or high, they will be more likely to engage in behaviors to lessen the problem from occurring (or reduce its severity). For example, avoiding an avalanche zone in a marked ski slope area because weather conditions have been documented visually and experienced personally.

The Extended Parallel Process Model explains how an individual will process and respond to a risk message by highlighting both the emotional and cognitive aspects of message processing that directly contribute to the acceptance of a message, and either triggers a danger control or a fear control (Witte, 1992). Danger control is defined when a person perceives that the severity and susceptibility of risk are high and also perceives a progressive action to control the "danger" involved (Witte, 1992). For example, the individual facing the threat is lead to focus on containing or ignoring their fear instead of creating strategies to eliminate or reduce the danger (Witte, 1992). In contrast, fear control is when a person is faced with danger and yet believes that they cannot take any protective action, so instead chooses to engage in a defensive mechanism in reducing their fear, instead of protective action to lessen the threat (Witte, 1994). For example, an individual turns their attention outward, while also adopting strategies to cope with the problem. Often, fear appeals in messaging are intended to elicit fear by confronting consumers with a threat (Hartmann, Apaolaza, D’Souza, Barrutia \& Echebarria, 2014). Ultimately the threat creates concern for an individual's own physical or psychological 
well-being, the well-being of others, or relationships with others (Brooker, 1981).

According to Witte (1992), a danger or fear control response will be activated by being communicated about a risk via a message from an external source or by the threat directly.

In summary, according to EPPM, several factors are central to how people perceive risk, including self-efficacy, response-efficacy, susceptibility, and severity. These risk perceptions have been shown to influence how people engage with communication surrounding said risks. To effectively engage the Portland public surrounding the health risks of air pollution, then, understanding their risk perceptions surrounding air pollution using an EPPM framework is essential.

Figure 1.1

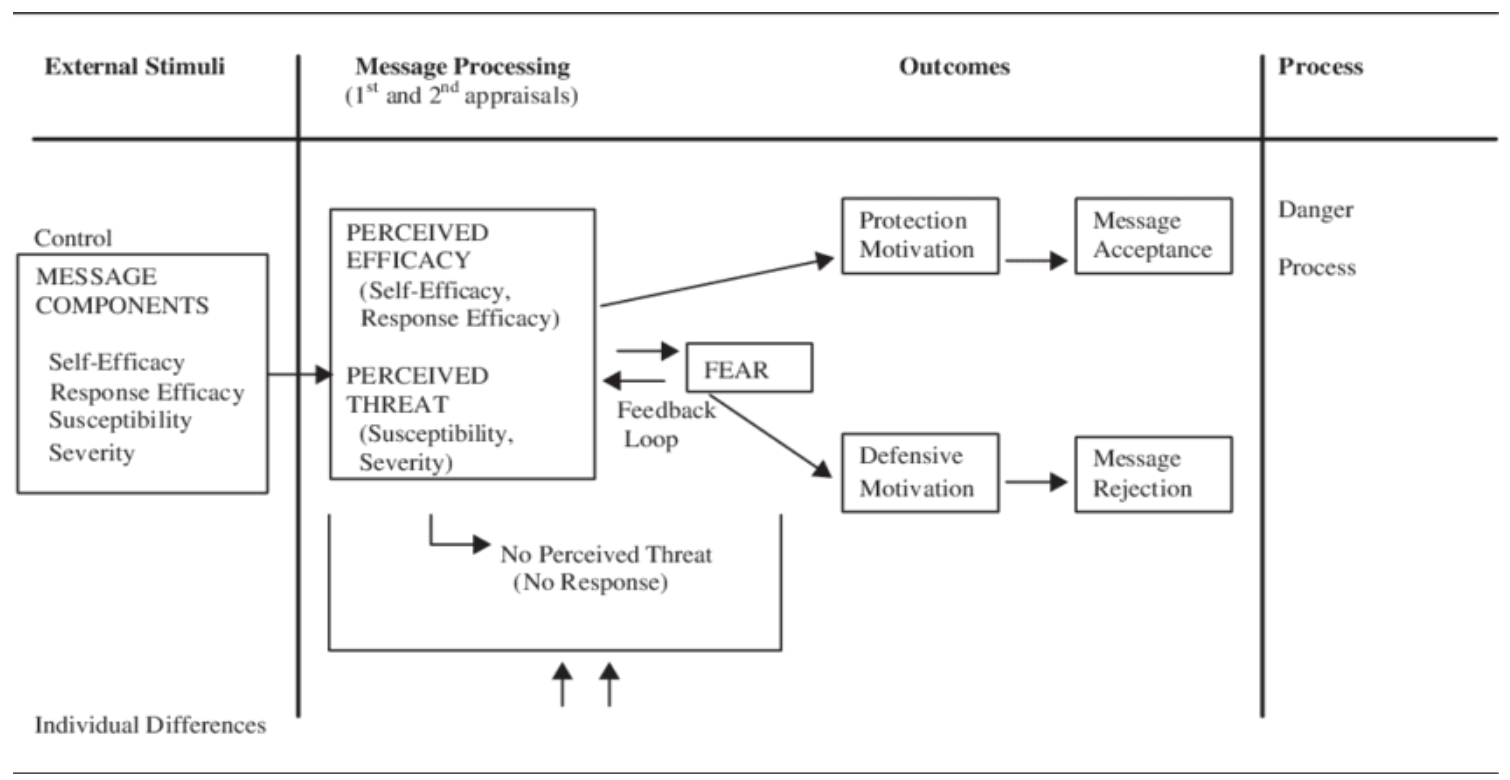

Witte's 7 Extended Parallel Process Model (EPPM). 


\section{EPPM and Environmental Risks}

This section discusses how EPPM is beneficial and progressive to the evaluation of environmental risks in communities. As referenced above, the consequences of air pollution for public health are associated with a broad spectrum of acute and chronic health effects, including increased respiratory symptoms, reduced lung function, increased number of hospitalizations, and an increased number of deaths from respiratory disease (Bernard, Samet, Grambsch, Ebi \& Romieu, 2001; EPA, 2019; Mehta, Shin, Burnett, North \& Cohen, 2013; Ostro \& Rothschild, 1989). Specific to this study, particulate air pollution, which is found mainly in urban ambient (outdoor) airflow, is related to serious health effects such as lung cancer and cardiopulmonary mortality (Mehta et al., 2013). While the issue of poor air quality, like many other environmental issues, is global in scale, it is localized in the physical, social, and cultural context in which communities live, work and interact directly with one another (Bickerstaff \& Walker, 2001).

The Extended Parallel Process Model has been primarily used to understand how individuals perceive health risks (Basil, Basil \& Deshpande, 2013; Gore \& Bracken, 2005; Popova, 2012). For example, a study completed by Von Gottberg, et al., (2016), assessed employees' willingness to come to work during a health pandemic, was effectively evaluated using EPPM. One thousand five hundred and sixty-six employees of a major German city participated in a cross-sectional online survey. The questions of the survey covered the dimensions of risk perception, role competency, self-efficacy, role importance, sense of duty, and willingness to report to work in the event of an infectious pandemic. Data involved in the study were analyzed by means of path analyses. (Von 
Gottberg, et al., 2016). It may seem evident that during a health crisis, it is not only necessary but imperative for community safety that public health workers report to work to maintain essential public health services during a health scare outbreak or global pandemic. The study concluded that $20 \%$ of public service and healthcare workers were not willing to come to work during an infectious pandemic. Their willingness to arrive at work was strongly influenced by their perception of a high self-efficacy in expectations and a high sense of personal and social duty. If the workers felt like they had options to protect themselves from the health scare outbreak and could indeed stay safe, they had a greater urgency to show up and protect not only themselves but also the communities around them. Workers were negatively impacted to show up for their shifts when they perceived that the risk of becoming infected at work or infecting family members was too high. For example, a lack of personal protective equipment would negatively impact their willingness to perform their skilled work. Fight or flight, which is often driven by fear, on both an individual and community-based level drives our actions towards overall safety.

Environmental risks have garnered increased attention from researchers, policymakers, and the public, worldwide (Jones \& Dunlap, 1992; Wakefield, Elliott, Cole \& Eyles, 2001), and air pollution is currently increasing in interest and focus for change in the United States. A federal study run by the US Environmental Protection Agency (EPA) to assess ambient concentrations, human exposures, and estimated risks of a wide range of air pollutants has conclusively found that millions of people are currently living in areas where air toxics pose significant health risks (Weinhold, 2002). The National Scale Air Toxics Assessment (NATA) found that the risk of developing any type of cancer over a lifetime due to exposure to certain air toxics exceeded 10 in 1 million for 
the United States (Weinhold, 2002). This is substantially higher than the EPA's goal of 1 in 1 million and has thankfully caused the attention of many scientists and the public as they strive for cleaner air and healthier communities.

While primarily focused on health risks, EPPM has also been used in several studies to examine public perception of environmental hazards. Xue, Hine, Marks, Anthony, Philips, and Nunn (2016), for example, employ EPPM to investigate the effectiveness of combining threat and efficacy messages to increase public engagement within the challenging topic of climate change. In this study, a total of 515 Mandarinspeaking residents of Beijing, China, were randomly assigned to view one of two climate change messages which were sourced from an online environmental website. The first message was presented as (high threat to low efficacy) and described the negative impacts of climate change transpiring in China daily but did not provide any information on what actions could or should be taken by citizens to reduce the threat. The second message (high threat to high efficacy) provided the same information, but also included practical information on how the individuals can immediately reduce the threat. After viewing the climate change message, the respondents evaluated the messages in terms of if they increased perceived efficacy, and elicited danger control and fear control response. All of the responses were assessed on 7-part scales. Perceived efficacy was assessed by four items that measured respondents' perceptions about how capable the recommendations of the message could be put into action (response efficacy) and the extent to which the message made them feel ready to deal with climate change (selfefficacy) effectively. At the completion of the study, it was concluded that the viewers who received a high threat to high efficacy message, with information on how to reduce 
the threat, experienced higher levels of perceived efficacy. In summary, the viewers were more motivated to find a solution to lessen their fear of climate change effects when the information was given of the forecasted threat.

In another study completed by Li (2014), a closer look at fear appeals and college students' attitudes and behavioral intentions toward global warming are unpacked. Global warming, similar to air pollution, is an environmental issue that has received a solid base of attention from scholars and policymakers worldwide because it poses a severe threat to human life and has gradually and definitively altered the ecological balance of the earth. Also similar to global warming, air pollution calls on the actions of humans and their daily activities to engage in acts that improve air quality and change the negative impact of air pollution on the earth and in our communities (Carvalho, 2007). Based on findings from empirical studies, the study by Li (2014) expects that perceived severity, perceived susceptibility, perceived response efficacy, and perceived self-efficacy should have a positive and individual effect on attitude changes and behavioral intentions. Three hundred forty-one students from six communication courses at two private universities in northern Taiwan were recruited for the experimental study. This study relied on a database of global warming news, which contains 2,281 news stories on global warming reported by Taiwan's major news media from 1998 to 2010 (Li \& Huang, 2012). The pretest questionnaire included questions that measured the attitudes and behavioral intentions toward global warming as well as basic demographic questions. After deleting those students who did not fill out the pretest or posttest questionnaires and those students who did not agree to participate in the posttest, this study obtained 263 valid questionnaires. In direct relation to Witte's EPPM, this specific study used the means for 
perceived threat (perceived severity + perceived susceptibility) and perceived efficacy (perceived response efficacy + perceived self-efficacy) to classify all students into one of four groups: the HH (high-perceived threat and high perceived efficacy), the HL (high perceived threat and low perceived efficacy), LH (low perceived threat and high perceived efficacy) and LL (low perceived threat and low perceived efficacy) group. The study found that students' perceived severity was not related to any of the attitudes or behavioral intentions. In past studies, it has been found that EPPM created an atmosphere that perceived severity and perceived susceptibility as separate dimensions (De Hoog, Stroebe, \& de Wit, 2007). In conclusion, this study is illuminating on the topic of environmental change and EPPM. It found that the perceived response efficacy was the most powerful predictor of global warming because it was positively correlated with the two attitudes and two behavioral intentions. However, this study also found that perceived self-efficacy was associated only with behavioral intentions, but it did not have any effects on the attitudes. The main difference between the question items for attitudes and the items for behavioral intentions include that the items for behavioral intentions asked the respondents whether they were willing to perform several actions that were all able to prevent global warming. Similar to what we would expect to find in a questionnaire regarding air pollution. The findings indicate that most students in this study were willing to make personal efforts to prevent global warming, but they were not confident that other people were capable of making these same efforts. As we have mentioned in this study, perceived self-efficacy refers to the degree to which the students believe that they had the ability to carry out the actions recommended by the messages. 
The study found and reiterated that the students felt that they were more likely to be affected by the desirable message than others were.

Communities would arguably benefit from becoming more engaged and educated regarding the complicated relationship between air quality and poor health (Kelly, Fuller, Walton \& Fussell, 2012). The challenge, however, lies in engaging the public and creating a sense of awareness and importance that enacts change on a micro and macro level, without initiating a fear-control response. The Extended Parallel Process Model, explains and predicts the likelihood of how an individual perceives that air pollution is a problem, that those same individuals perceive they are susceptible to risks associated with poor air quality, and if they have the capability to protect themselves from those risks. Given the important role technological advancements are likely to play in the management of air pollution, it is also important to understand how public perception of science and technology relates to concepts in EPPM.

\section{Confidence in Science and Technology}

This section discusses the importance of evaluating audiences and understanding the general perception of positive and negative aspects of science and technology advancements. In the last several decades, science and technology have experienced an extreme range of growth. Beginning in the 1970s, environmental sociologists have individually examined the role of science and technology as it relates to the public's perception of usefulness and the environment (Xiao, 2013). Perceived usefulness is the

degree to which an individual believes that using a particular system, in this case, science and technology will enhance or aid in performance, such as solutions toward a global crisis of air pollution (Chen, Lin, Yeh \& Lou, 2013). The science community has become 
increasingly concerned with the potential of a weakened belief or confidence in science and technology that may undermine its legitimacy and movement for successes in advances (Rayner, 2010). However, evidence suggests that Americans have reported a high level of confidence in science and technology. Over the past 40 years, more than 80 percent of US adults have held a positive view of the benefits of science and technology (Miller, 2004). Continued studies and evidence suggest that Americans view science and technology as improving opportunities for themselves and their children (Miller, 2004). National samples of Americans have been asked the question, "Because of science and technology, there will be more opportunities for the next generation" with the option to agree or disagree with the statement. More than three-quarters of US adults conclusively agreed with this statement in 1985, and more than 90 percent have agreed with this view through the 1990s (Miller, 2004; NSB, 2000). According to the National Science Board (2000), U.S. Citizens have routinely held optimistic views of science and technology since the 1970s. That is, we tend to frame public confidence in science and technology as being high as positive, and confidence in science and technology being low as negative (Funk, Hefferon, Kennedy \& Johnson, 2019). Importantly, high confidence in science can have negative consequences for successfully responding to environmental risks. In a study completed by York and Clark (2010), the authors take a close look at technological optimism, and they argue that technological optimism is somewhat misguided and does a poor job of addressing our world's environmental crises. They advocate for and emphasize the importance of natural science to help communities understand the world but also recognize the importance of challenging the manipulation of science by the "elite" (York \& Clark, 2010). 
Besley (2013) overviewed current public opinion regarding science and technology and found that there is considerable gravity in studying science and technology. The key role and importance of studying science and technology are driven by the central role that innovation plays a large part in the global success and the recognition that fostering innovation requires a supportive social environment (Besley, 2013). Understanding and attitudes exist from the primary role that innovations play an essential part in our everyday lives. Many scientists who aim to contribute to the overall framing of environmental controversies cover topics such as climate change, air pollution, and health research through outlets such as blogging political activism, and other forms of public commentary. This inherently shapes our society's interpretations about why an environmental issue may or may not be a problem, who or what is to blame, and what should be done to "fix the problem" at hand (Nisbet \& Mooney, 2007; Nisbet \& Scheufele, 2009). Importantly, additional studies have shown significant concern among the public understanding of science and technology usage and the confidence that in the long term, they will be beneficial (Miller, 2004).

Per Xiao (2013), few empirical studies examine whether or not perceptions of environmental risks, like air pollution, are associated with reduced or increased confidence in science and technology. Understanding this relationship is essential because it aids communities in the ability to create new technology and may inform science communication practices relative to technological developments that have implications for air quality risks. High confidence in science and technology may be associated with lower perceptions of environmental risk severity and susceptibility. If, for example, an individual believes that scientific and technological developments will clean 
all of the plastic out of the ocean, they may be less inclined to believe that plastic pollution is a severe risk and that they are susceptible to it. However, it's also possible that one may hold the same belief about science and technology and experience increased risk perceptions as a result, believing the problem to be so severe that science and technology are required in the first place for it to be utilized. Understanding these dynamics is important because it may influence the efficacy of communication efforts aimed at addressing public risk perceptions. Additionally, it may illuminate a negative consequence for science communicators whose goal is to increase public confidence in science and technology, as that public confidence may then negatively influence environmental risk perceptions, which will, in turn, influence human behavior toward the environment. Confidence in science and technology is defined in this study as the belief that science and technology can and will solve all environmental problems currently and repair future damage to the environment (Milfont \& Duckitt, 2010).

\section{Research Questions}

Due to the efficacy of EPPM to understand public perception of risk and the unclear but arguably important role of confidence in science and technology in those perceptions, I offer the following as research questions:

RQ1: What is the relationship between confidence in science and technology and the perceived severity of air pollution?

RQ2: What is the relationship between confidence in science and technology and perceived susceptibility to air pollution?

RQ3: What is the relationship between confidence in science and technology and perceived self-efficacy ${ }^{l}$ regarding air pollution?

\footnotetext{
${ }^{1}$ EPPM distinguishes two types of efficacy: self and response. Response efficacy (as described in the literature review) refers to the effectiveness of a specific course of action. Because I was not surveying participants about a specific course of action, response efficacy was not measured.
} 


\section{Methods}

\section{Participants}

To answer the aforementioned research questions, data were collected from early March through early April 2020 via an online survey administered through Qualtrics in partnership with the City of Portland ${ }^{2}$. This research was reviewed and approved by the Portland State University IRB procedure ${ }^{3}$. The population of interest was respondents who live within the city limits of Portland, Oregon, and were recruited using a Qualtrics survey panel. The online survey measured Portlander's risk perceptions as defined by the EPPM (perceived severity, perceived susceptibility, and self-efficacy) and confidence in science and technology to solve environmental problems. Participants $(n=1000)$ were residents of Portland, Oregon, and were compensated up to $\$ 5$ for their participation. Participants were sampled using a random and quota technique to ensure racial representation; 7,359 people were invited to participate, lending a response rate of $13.6 \%$. On average, participants took 27 minutes to complete the survey. Participants who demonstrated a lack of engagement with the survey (e.g. 'straight-lining') and those who failed one or both attention checks embedded within the survey were removed. Participant ages were collected using interval options (18-24, 25-34, 35-44, 45$54,55-64$, etc.) with the 'average' interval of 35-44. Participants were half female $(50 \%)$, male $(49.7 \%)$, and intersex $(0.03 \%)$ adults. Participants were primarily white $(79 \%)$ and

\footnotetext{
${ }^{2}$ The survey was developed through a partnership between Portland State University, the City of Portland (Smart City PDX), and Portland General Electric. This research was funded by Portland State's Digital City Testbed Center, the College of Liberal Arts and Sciences, and Portland General Electric. This research was designed to gain a better understanding of public perception of air pollution, and public attitudes toward science and the environment in Portland, Oregon. The goal of this work is to inform responsive public engagement strategies for the City of Portland.

${ }^{3}$ https://sites.google.com/a/pdx.edu/research/integrity/hrpp
} 
non-Hispanic (93\%). Other racial identities included black (6\%), Asian (9.1\%), American Indian or Alaska Native (5.9\%), and Native Hawaiian or Pacific Islander (1.2\%). The average education of participants was "some college" $(\mathrm{M}=3.73, \mathrm{SD}=1.519)$. The average income of participants was $\$ 40,000-49,999(\mathrm{M}-5.00, \mathrm{SD}=2.21)$. The study was a direct reflection of Portland, Oregon demographics after confirming with a government census bureau report (U.S. Census Bureau QuickFacts: Portland city, Oregon, 2019). The governmental census bureau reports that Portland, Oregon is also half female (50.5\%), and male (49.5\%) adults. Race information for the city of Portland is documented as, White (77.1\%), Black or African American (5.8\%), American Indian and Alaska Native (0.7\%), Asian (8.1\%), and Hispanic or Latino (9.7\%) (U.S. Census Bureau QuickFacts: Portland city, Oregon, 2019).

\section{Measures}

Participants were asked questions about their confidence in science and technology and air quality risk perceptions. All items were measured using a 5-part Likert scale. For a list of the survey items used in the current study, see Appendix A.

Confidence in Science and Technology: A pre-existing and previously used and validated 10-item scale (Milfont \& Duckett, 2010) was used to measure the confidence in science and technology. Participants indicated their perceptions in science and technology on how much they agree or disagree shown on a 5-part scale from 1 (strongly disagree) to 5 (strongly agree) to the following statements:

1. Most environmental problems can be solved by applying more and better technology.

2. Science and technology will eventually solve our problems with pollution, overpopulation, and diminishing resources.

3. Science and technology do as much environmental harm as good. 
4. Modern science will NOT be able to solve our environmental problems

5. We cannot keep counting on science and technology to solve our environmental problems.

6. Humans will eventually learn how to solve all environmental problems.

7. The belief that advances in science and technology can solve our environmental problems is completely wrong and misguided.

8. Humans will eventually learn enough about how nature works to be able to control it.

9. Science and technology cannot solve the grave threats to our environment.

10. Modern science will solve our environmental problems

A reliability coefficient is a measure of how well a test measures achievement. The items had high reliability $(\alpha=0.802)$ (Kelley, 1942) and were averaged to create a single 'confidence in science and technology' score for each participant $(\mathrm{M}=2.98, \mathrm{SD}=0.694)$, such that a higher score indicates more confidence in science and technology.

Severity: Severity, the perceived impact that poor air quality has on individuals, was measured on a 3-item scale with the answer choices rated on a 5-part Likert scale ranging from 1 = strongly disagree to, 5 = strongly agree. The survey questions included:

1. I believe that air pollution in my neighborhood is severe.

2. I believe that air pollution in my neighborhood is serious.

3. I believe that air pollution in my neighborhood is significant.

The items had high reliability $(\alpha=0.91)$ and were averaged to create a single 'severity' score $(M=2.347, S D=1.113)$, such that a higher score indicates higher perceived severity (Kelley, 1942).

Susceptibility: Susceptibility, the likelihood that poor air quality will impact individuals was measured on a 3-item scale with the answer choices rated on a 5-part Likert scale ranging from $1=$ strongly disagree to, $5=$ strongly agree. The survey questions included:

1. I am at risk of suffering from air pollution.

2. It is likely that I will suffer from air pollution 
3. It is likely that I will suffer health problems because of air pollution.

These items had high reliability $(\alpha=0.91)$ and were averaged to create a single

'susceptibility' score $(\mathrm{M}=2.91, \mathrm{SD}=1.143)$, such that a higher score indicates higher perceived susceptibility (Kelley, 1942).

Self-efficacy: Self-efficacy, a feeling of competency to perform the tasks needed to protect oneself from poor air quality, was measured on a 3-item scale with a 5-part Likert scale ranging from $1=$ strongly disagree, to $5=$ strongly agree. The survey questions included:

1. I feel confident that I can protect myself from air pollution.

2. Protecting myself from air pollution is easy to do.

3. Protecting myself from air pollution is convenient.

Scale items had adequate reliability $(\alpha=0.74)$ and were averaged to create a single 'selfefficacy' score $(\mathrm{M}=2.873, \mathrm{SD}=.861)$, such that a higher score indicates higher levels of self-efficacy (Kelley, 1942). 


\section{Results}

Data were analyzed using the Statistical Package for the Social Sciences. For research question 1, I asked if there is a relationship between confidence in science and technology and the perceived severity of air quality risk perception. To answer RQ1, I ran a Pearson Product Correlation for confidence in science and technology and perceived severity. I found a statistically significant and negative correlation between the two variables $(\mathrm{r}=-0.102, \mathrm{p}<0.01)$, indicating that higher confidence in science and technology is associated with lower perceived severity.

For research question 2, I asked if there is a relationship between confidence in science and technology and perceived susceptibility to air quality risk perception. A correlation analysis was used to quantify the association between two variables. To answer this question, I ran a Pearson Product Correlation for confidence in science and technology and perceived susceptibility to air pollution. I found a statistically significant and negative correlation between the two variables $(\mathrm{r}=-0.107 \mathrm{p}<0.01)$, indicating that higher confidence in science and technology is associated with lower perceived susceptibility.

For research question 3, I asked if there is a relationship between confidence in science and technology and self-efficacy regarding air quality risk perception. To answer this question, I ran a Pearson Product Correlation for confidence in science and technology and self-efficacy. I found a statistically significant, positive correlation between the variables $(\mathrm{r}=0.144, \mathrm{p}<0.001)$, indicating that higher confidence in science and technology is associated with higher perceived self-efficacy. 


\section{Discussion}

To meaningfully engage publics regarding environmental risks like air pollution, it is important to understand community perceptions of those risks and their technological solutions. Per Sagoff (1990), environmental issues are moral, civic, and communal problems, requiring communities to come together in a common understanding of future scientific and technological advancements (Smith, Schuenerman \& Zidberg, 1964). The current health risk of poor air quality and a simultaneous rise in technological advancements aimed toward improving air quality point to a need to better understand public opinion dynamics. Understanding public perception toward air quality as well as science and technology are critical for successful citizen involvement as shifts toward new technologies continue to take place.

Although very few studies and surveys have been conducted to systematically study public perceptions related to air pollution, the urgency and importance should not be ignored. This study examined how people living in Portland, Oregon perceive air pollution as an environmental risk and examines the extent to which those risk perceptions relate to confidence in science and technology. I found that confidence in science and technology is positively correlated with self-efficacy, and negatively correlated with perceived severity and susceptibility. In other words, I found that higher confidence in science and technology is associated with feeling like one can protect themselves from air pollution and feeling like air pollution is not a severe risk that one is susceptible to. Conversely, perceptions of high severity and susceptibility are associated with lower confidence in science and technology. 


\section{Implications for Community Engagement}

Based on these findings, that higher confidence in science and technology elicits the ability to protect oneself from air pollution and that air pollution is not as high of an individual risk, complex issues such as air pollution and how science and technology advancements are easing individual risk must be communicated effectively. Currently, the City of Portland operates three programs that achieve significant reductions of air toxins from vehicles: The Employee Commute Options Program, the Vehicle Inspection Program, and the Oregon Low Emission Vehicles Program (Air pollution, Oregon.gov). Although these programs have made significant strides in state and local regulatory levels for air toxics health-based ambient benchmark concentrations, there is a need for additional work to improve those numbers (Air pollution, Oregon.gov). Prior research suggests that communicating improvements that have been made because of newer regulations, like the programs listed above, have the potential to increase compliance and the understanding that science and technology innovations create city-wide health improvements (Frieden, 2014). The results from the current study suggest that communication about technological advancements, assuming that communication increases confidence in science and technology, might be associated with lower threat perceptions. Practitioners looking to communicate about technological advancements within the context of environmental risks ought to keep these relationships in mind, especially when those environmental risks persist alongside that technology. Cities can use air quality information and emissions data, gained through technical information such as air sensors, to guide planning decisions in ways that also reduce resident's exposure to air pollution. 
It is important to note that the state of Oregon has the third-largest population at risk of excess cancer due to air pollution in the United States (EPA, 2014). Despite the incredible visual landscape of lush green trees, inspiring mountain ranges, and blue skies, Portland's air is, in fact, much "dirtier" and poorer quality than originally thought and understood by the general population. This study reflects that public perception of the risk may not match the actual risk at hand. Data has shown that severity and susceptibility perceptions were somewhat low. Therefore, public perception of air pollution risk may not match the actual risk. For example, results from this study point to the conclusion that the perceived air pollution severity or risk and the susceptibility that it will harm the individual is low. Importantly, given the negative correlation between threat perceptions and confidence in science and technology, the more confidence someone has in science, the more 'out of sync' they may be in their accurate risk assessment of air pollution in neighborhoods and communities and the health effects that have the potential to occur within accurate risk assessments.

Despite air pollution in Portland being a demonstrable health risk, specific to a study completed by the American Lung Association's "State of the Air" 2019 report finding that the Portland metro area is currently the $23^{\text {rd }}$ polluted area in the United States for short-term particle pollution, other studies have similarly demonstrated that Portlanders on average do not understand the risks associated with their daily activities and health (Harvey, 2019). Communication efforts aimed toward engaging Portlanders' surrounding air pollution, then, should emphasize the severity and susceptibility of that risk. When communicating about science and technology, it is possible that communicating about scientific advancements functions to reduce risk perceptions. 
Though this study isn't causal, the significant relationship shown here suggests the potential for a causal connection.

Confidence in science and technology, although mainly positive, may also cause an individual to fear their risk of air pollution and associated hazards. This in turn can create the illusion of a false belief that their city possesses the innovative efforts and advancements to protect their health without further personal efforts and education (Carolan, 2008). Self-efficacy of air pollution control and the ability to safeguard the prevention of its health effects should be carefully crafted in city-wide efforts and communication. Self-efficacy is directly concerned with an individual's perceived capability, or the belief that an individual can personally protect themselves or make a difference, which can be a major determinant of behavioral intention. Given the significant relationship found here, individuals may possess a high self-efficacy because they have confidence in science and technology and its current and future advancements. However, it is possible also that because they have confidence in science and technology and possess high efficacy they do not feel in control of future change or health outcomes outside of their person. The understanding and belief that an individual can create change on a community and personal level are integral for action and overall community health.

\section{Implications for Research}

In what follows, I discuss study results in relation to current research regarding confidence in science and technology, self-efficacy, severity, and susceptibility.

\section{Confidence in Science and Technology}

This study concludes that the more confident someone is in science and technology, the less severity and susceptibility they recognize, and the higher the self- 
efficacy they perceive to protect themselves and others from harm. Because of the significant correlation between confidence and risk perceptions, these results indicate the possible utility of attending to these dynamics in future work. For example, when studying risks that have (or may not have) technological solutions, individuals' views of those risks will possibly be related to their views regarding those solutions. Future work should include an understanding of confidence in science and technology if the researchers are trying to understand risk perceptions, especially when communication efforts include technological solutions.

It is also important to guard against situations in communication that look at an exaggerated optimism in technological advancements. For example, York and Clark (2010), argue that technological optimism is misguided and a true hazard when perceived efficacy is reliant on confidence in science and technology. Which also performs poorly in addressing our world's environmental crises, such as air pollution. The connections between science, technology, and environmental problems are highly complex and integrated. A few scholars, who remain skeptical of science and technology, take a firm and somewhat anti-realist stance on internal confidence, rejecting the possibility of concrete knowledge of the natural world and the hazards surrounding us (Tester, 1991; Woolgar, 1988). If this is the case, it is argued that human knowledge, such as air pollution hazards and health effects, is merely a social construction (York \& Clark, 2010). Optimism in science and technology has the potential to lead toward the belief that environmental problems such as air pollution can be remedied by science and technology breakthroughs and that these advancements will not lead toward even more serious environmental problems (Ausubel, 1996; Carolan, 2008). This study indicates that when 
an individual has high confidence in science and technology that they also have a high perceived self-efficacy in their ability to protect themselves from the hazards of air pollution. The combination of confidence in science and technology boosts a person's confidence that there are advances in technology that will aid their current and future health implications from poor air quality. It is important to protect against exaggerated high confidence in science and technology which may be associated with lower perceptions of environmental risk severity and susceptibility (York \& Clark, 2010). Future research may benefit from evaluating communication methods to bridge the gap between overconfidence in science and technology and environmental protection.

We know from past studies (e.g. Besley (2013) that a key role in studying science and technology has shown significant concern among the public's understanding of science and technology usage and how confidence in science and technology, which per our study relates to high self-efficacy, will be beneficial. A primary importance of studying science and technology is to understand attitudes acquired from the key role that new innovations play in scientific advancements. And to highlight the importance that having a supportive environment and bolstering understanding impacts community holistically. Challenges of assessing science and technology arise when the importance is focused on knowledge that is difficult to achieve and may not be associated with science and technology acceptance (Bauer et al., 2007; Druckman \& Bolsen, 2011). Future studies may benefit from further investigation on how to engage publics on the importance of innovation efforts while continuing to communicate the real-time needs of environmental hazards in the City of Portland. 


\section{Self-efficacy}

As referenced above, self-efficacy is the belief that an individual possesses the ability to follow through with the recommended response to avoid the threat or problem being addressed (Gore \& Bracken, 2005; Popova, 2012). The results from this current study fall in line with Xue et al (2016), who employed EPPM to investigate the effectiveness of combining threat and efficacy messages to increase public engagement within the challenging topic of climate change. These researchers also found that those respondents who received a high threat to high efficacy message, with information on how to reduce their threat to climate change, experienced higher levels of perceived selfefficacy. The respondents of Xue et al (2016) study were more motivated to find a solution to lessen their fear of climate change effects when the information was given of the forecasted threat.

As I have related in the above information, in previous academic studies it has been demonstrated that high perceived threat or severity combined with low perceived self-efficacy has resulted in complete message rejection and a boomerang response (Witte, 1992). For example, it is possible that when fear control processes begin to dominate, the individual responds to the fear and not to the danger. They do not perceive that they can effectively alleviate the threat of air pollution and instead downplay the hazard by avoidant or dismissive behaviors. This study demonstrated that higher confidence in science and technology is associated with higher perceived self-efficacy. The more confident respondents are in science and technology; the fewer risk individuals recognize to their person and communities around them. It would be advantageous to 
continue studies reflecting on confidence in science and technology and how this relates to self-efficacy, an individual's ability to take action, both short and long term.

\section{Severity}

Perceived severity is the belief regarding the significance or magnitude of the threat, beliefs concerning the consequences of compliance or not complying regarding a specific event (Popova, 2012; Witte et al., 1996). Perceived severity refers to the understanding or cognition, separate from emotions that a threatening event such as air pollution can and will cause harm. Per a study completed by Witte, Berkowitz, Cameron, and McKeon (1998) individuals were found with low threat perception toward motivation and healthy behaviors, it did not matter if they were exposed to a fear appeal or educational information towards health effects. There was in fact, no significant difference in the individual's attitudes and intentions or avoidance of the health effect dependent on risk messages toward behavior change (Popova, 2012). In a similar study, Wong and Cappella (2009) operationalized an experiment where both threat and efficacy were utilized as message attributes. It was found that when message threat is low, intentions to quit smoking did not vary as a function of the perceived level of selfefficacy. Relevant to this study this echo's the respondent's level of confidence of science in technology as being high and lowering their perceived severity.

Message delivery is imperative when formulating communication regarding science and technology and the advantages and disadvantages and is directly relevant to an individual's confidence in an action or evaluation of severity level. However, several studies have found no effects of perceived severity on attitudes, intentions, or behaviors. For example, in a survey of Texas farmers, Witte et al. (1993) found no effect of threat, 
only of efficacy. Individuals with a high level of self-efficacy perceptions had a much higher attitude, intentions, and behavior regarding tractor safety and the importance of changing current safety protocols and behaviors. How a message is delivered is imperative to a further understanding of the risk. While this study did not measure behavioral intention, it is possible that confidence in science and technology functions as a moderator linking the relationship between perceived severity and protective behaviors. The results from the current study point to a need for further research to be completed on the exact impact of perceived severity for air pollution on attitudes, intentions, and behaviors within the context of confidence in science and technology.

\section{Susceptibility}

Perceived susceptibility is the belief regarding an individual's risk of actually experiencing the threat (Popova, 2012; Witte et al., 1996). This study indicates that higher confidence in science and technology is associated with lower perceived susceptibility regarding the health effects of air pollution. Often the manipulation of a message to communicate health risks directly affects an individual's response to communication efforts. Detailed by Witte et al (1996), in a study regarding the health implications of AIDS information was utilized describing the life-threatening disease using vivid language and personal susceptibility was highlighted by demonstrating visual imagery and presenting the climbing rates of HIB in college students (Witte, 1994). If there is no information or solution given as it relates to efficacy and recommended actions, individuals will rely on past experiences and previous beliefs to determine their perceived efficacy. Higher confidence in science and technology is associated, per this study, with lower perceived susceptibility regarding the health effects of air pollution and 
the ability to change current and future behaviors. Future research is needed to better understand at what point an individual is motivated to create change, what creates a personal message system to enact change, and the complete understanding of the negative health effects experienced by air pollution.

\section{Conclusion}

Within this study, I set out to better understand the relationship between public perception of risk and the influence of confidence in science and technology and how it affects those perceptions. This study concludes that the more confident someone is in science and technology, the less threat (severity and susceptibility) they recognize, and the higher the self-efficacy they perceive. The primary takeaway from the current study is that the higher confidence an individual has in science and technology equates to stronger confidence in scientific and technological advancements and the ability for innovations to protect themselves and their communities from applicable environmental health and societal risks. It is believed that the technology itself will guard against future health effects and implications. These results carry important connections for practitioners looking to engage the Portland public surrounding air pollution and related technological advancements. 


\section{References}

7 million premature deaths annually linked to air pollution. (2014, March 25). Retrieved from https://www.who.int/mediacentre/news/releases/2014/air-pollution/en/

10 Tips to Protect Yourself from Unhealthy Air. (n.d.). Retrieved from https://www.lung.org/our-initiatives/health-air/outdoor/air-pollution/10-tips-toprotect-yourself.html

2014 NATA: Assessment Results. (2018, August 27). Retrieved from https://www.epa.gov/national-air-toxics-assessment/2014-nata-assessment-results

Air Pollution: Current and future challenges. (2019, September 17). Retrieved from https://www.epa.gov/clean-air-act-overview/air-pollution-current-and-futurechallenges

Air Quality. (n.d.). Retrieved September 04, 2020, from https://www.oregon.gov/deq/aq/Pages/AQ-Portland.aspx

Ambient (outdoor) air pollution. (2018, May 2). Retrieved from https://www.who.int/en/news-room/fact-sheets/detail/ambient-(outdoor)-airquality-and-health

American Chemical Society. (2018, October 17). Moss rapidly detects, tracks air pollutants in real-time. ScienceDaily. Retrieved August 31, 2020, from www.sciencedaily.com/releases/2018/10/181017111027.htm

Arrow, K., Bolin, B., Costanza, R., Dasgupta, P., Folke, C., Holling, C. S., ... \& Pimentel, D. (1995). Economic growth, carrying capacity, and the environment. Ecological Economics, 15(2), 91-95. 
Ausubel, J. H. (1996). Can technology spare the earth? American Scientist, 84(2), 166178.

Baer, A. (2017, December 12). Portland, Oregon's Toxic Air Problem. Retrieved from https://www.opb.org/news/series/portland-oregon-air-pollution-glass/

Bandura, A., \& Walters, R. H. (1977). Social Learning Theory (Vol. 1). Englewood Cliffs, NJ: Prentice-hall.

Barnett, D. J., Thompson, C. B., Semon, N. L., Errett, N. A., Harrison, K. L., Anderson, M. K., .. \& Mejia-Echeverry, A. (2014). EPPM and willingness to respond: the role of risk and efficacy communication in strengthening public health emergency response systems. Health Communication, 29(6), 598-609.

Basil, M., Basil, D., Deshpande, S., \& Lavack, A. M. (2013). Applying the Extended Parallel Process Model to workplace safety messages. Health Communication, 28(1), 29-39.

Bernard, S. M., Samet, J. M., Grambsch, A., Ebi, K. L., \& Romieu, I. (2001). The potential impacts of climate variability and change on air pollution-related health effects in the United States. Environmental Health Perspectives, 109(suppl 2), 199-209.

Besley, J. C. (2013). The state of public opinion research on attitudes and understanding of science and technology. Bulletin of Science, Technology \& Society, 33(1-2), 12-20.

Bickerstaff, K., \& Walker, G. (2001). Public understandings of air pollution: The 'localization' of environmental risk. Global Environmental Change, 11(2), 133145. 
Brauer, M., Amann, M., Burnett, R. T., Cohen, A., Dentener, F., Ezzati, M., ... \& Van Donkelaar, A. (2012). Exposure assessment for estimation of the global burden of disease attributable to outdoor air pollution. Environmental Science \& Technology, 46(2), 652-660.

Brooker Jr, G. (1981). A comparison of the persuasive effects of mild humor and mild fear appeals. Journal of Advertising, 10(4), 29-40.

Bureau, U. (2020, May 07). City and Town Population Totals: 2010-2019. Retrieved August 02, 2020, from https://www.census.gov/data/tables/timeseries/demo/popest/2010s-total-cities-and-towns.html

Carolan, M. S. (2008). The bright-and blind-spots of science: why objective knowledge is not enough to resolve environmental controversies. Critical Sociology, 34(5), 725-740.

Carvalho, A. (2007). Ideological cultures and media discourses on scientific knowledge: re-reading news on climate change. Public Understanding of Science, 16(2), 223243.

Chen, Y., Lin, Y., Yeh, R., \& Lou, S. (2013). Examining Factors Affecting College Students' Intention to Use Web-Based Instruction Systems: Towards an Integrated Model. Turkish Online Journal of Educational Technology - TOJET, 12(2), 111121.

Chen-gao, W. A. N. G. (2000). Air Pollution: An Invisible Killer to Human Health. Sichuan Environment, (4), 21.

Coleman, C. L. (1995). Science, technology, and risk coverage of a community conflict. Media, Culture \& Society, 17(1), 65-79. 
De Hoog, N., Stroebe, W., \& De Wit, J. B. (2007). The impact of vulnerability to and severity of a health risk on processing and acceptance of fear-arousing communications: A meta-analysis. Review of General Psychology, 11(3), 258285.

Elsom, D. (2014). Smog alert: managing urban air quality. Routledge Essays, UK. (November 2018).

Frieden, T. R. (2014). Six components necessary for effective public health program implementation. American Journal of Public Health, 104(1), 17-22.

Fuller, G. (2018, November 28). Air pollution: 'the invisible killer'. Retrieved from https://theecologist.org/2018/nov/27/air-pollution-invisible-killer

Funk, C., Hefferon, M., Kennedy, B., \& Johnson, C. (2019, December 30). Trust and Mistrust in Americans' Views of Scientific Experts. Retrieved from https://www.pewresearch.org/science/2019/08/02/trust-and-mistrust-inamericans-views-of-scientific-experts/.

Gangaas, K. E., Kaltenborn, B. P., \& Andreassen, H. P. (2015). Environmental attitudes associated with large-scale cultural differences, not local environmental conflicts. Environmental Conservation, 42(1), 41-50. doi: 10.1017/S0376892914000125

Gatziolis, D., Jovan, S., Donovan, G., Amacher, M., \& Monleon, V. (2016). Elemental atmospheric pollution assessment via moss-based measurements in Portland, Oregon. Gen. Tech. Rep. PNW-GTR-938. Portland, OR: US Department of Agriculture, Forest Service, Pacific Northwest Research Station. 55 p., 938. 
Giles, L.V., Barn, P., Kunzli, N., Romieu I., Mittleman M., van Eeden, S., \& Smargiassi, A. (2011). From good intentions to proven interventions: effectiveness of actions to reduce the health impacts of air pollution. Environmental Health Perspectives, $119(1), 29-36$.

Gore, T. D., \& Bracken, C. (2005). Testing the theoretical design of a health risk message: Reexamining the major tenets of the extended parallel process model. Health Education \& Behavior, 32, 27-41. doi: 10.1177/1090198104266901

Hartmann, P., Apaolaza, V., D’souza, C., Barrutia, J. M., \& Echebarria, C. (2014). Environmental threat appeals in green advertising: The role of fear arousal and coping efficacy. International Journal of Advertising, 33(4), 741-765.

Harvey, H. (2019, April). Portland Area Air Quality Worsens According to 'State of the Air' 2019 Report. Retrieved from https://www.lung.org/local-content/_contentitems/about-us/media/press-releases/portland-area-air-quality.html

Hodgson, A., \& Hitchings, R. (2018). Urban air pollution perception through the experience of social practices: Talking about breathing with recreational runners in London. Health and Place, 53, 26-33

Howard, R. (2016, September 10). 6 New Technologies Which Could Improve Urban Air Quality. Retrieved August 03, 2020, from https://policyexchange.org.uk/6-newtechnologies-which-could-improve-urban-air-quality/

Jones, R. E., \& Dunlap, R. E. (1992). The social bases of environmental concern: Have they changed over time? Rural Sociology, 57(1), 28-47. 
Kelly, F. J., Fuller, G. W., Walton, H. A., \& Fussell, J. C. (2012). Monitoring air pollution: Use of early warning systems for public health. Respirology, 17(1), 719.

Kelly, F. J., \& Fussell, J. C. (2015). Air pollution and public health: emerging hazards and improved understanding of risk. Environmental Geochemistry and Health, 37(4), 631-649.

Kelley, T. L. (1942). The reliability coefficient. Psychometrika, 7(2), 75-83.

Krosnick, J. A., Visser, P. S., \& Holbrook, A. L. (1998). American opinion on global warming. Resources, 133, 5-9.

Li, S. C. S. (2014). Fear appeals and college students' attitudes and behavioral intentions toward global warming. The Journal of Environmental Education, 45(4), 243257.

Linking Modern Technology to Global Pollution Environmental Sciences Essay. Retrieved from https://www.ukessays.com/essays/environmental-sciences/linking-modern$\underline{\text { technology-to-global-environmental-sciences-essay.php?vref }=1}$

Makri, A., \& Stilianakis, N. I. (2008). Vulnerability to air pollution health effects. International Journal of Hygiene and Environmental Health, 211(3-4), 326-336.

Mao, S., \& Vinson, V. (2018). Power couple: Science and technology. Science (New York, N.Y.), 361(6405), 864-865

Mehta, S., Shin, H., Burnett, R., North, T., \& Cohen, A. J. (2013). Ambient particulate air pollution and acute lower respiratory infections: a systematic review and 
implications for estimating the global burden of disease. Air Quality, Atmosphere \& Health, 6(1), 69-83.

Milfont, T. L., \& Duckitt, J. (2010). The environmental attitudes inventory: A valid and reliable measure to assess the structure of environmental attitudes. Journal of Environmental Psychology, 30(1), 80-94.

Miller, J.D. (2004). Public understanding of, and attitudes toward, scientific research: What we know and what we need to know. Public Understanding of Science, 13, 273-294.

Miller, J. D., \& Pardo, R. (2000). Civic scientific literacy and attitude to science and technology: A comparative analysis of the European Union, the United States, Japan, and Canada. Between understanding and trust: The Public, Science and Technology, 81-130.

Miller, J. D., Pardo, R., \& Niwa, F. (1997). Public perceptions of science and technology. A comparative study of the European Union, the United States, Japan, and Canada. Fundación BBV-Chicago Academy of Sciences, Bilbao.

Murray-Johnson, L., Witte, K., Patel, D., Orrego, V., Zuckerman, C., Maxfield, A. M., \& Thimons, E. D. (2004). Using the extended parallel process model to prevent noise-induced hearing loss among coal miners in Appalachia. Health Education \& Behavior, 31(6), 741-755.

National Science Board (2000) Science and Engineering Indicators - 2000. Washington: U.S. Government Printing Office. 
Ngo, N. S., Bao, X., \& Zhong, N. (2018). Local pollutants go global: the impacts of intercontinental air pollution from China on air quality and morbidity in California. Environmental Research, 165, 473-483.

Nisbet, M. C., \& Mooney, C. (2007). Framing science. Science, 316(5821), 56-56.

Nisbet, M. C., \& Scheufele, D. A. (2009). What's next for science communication? Promising directions and lingering distractions. American Journal of Botany, 96(10), 1767-1778.

O'Connor, A. (2019). The Invisible Killer. The Lancet Respiratory Medicine, 7(1), 17-18. Oregon Has Toxic Air Pollution. (n.d.). Retrieved from http://www.whatsinourair.org/ Ostro BD, Rothschild S. Air pollution and acute respiratory morbidity: an observational study of multiple pollutants. Environmental Research, 50:238-247 (1989).

Popova, L. (2012). The extended parallel process model: Illuminating the gaps in research. Health Education \& Behavior, 39(4), 455-473.

Prati, G., \& Zani, B. (2013). The effect of the Fukushima nuclear accident on risk perception, antinuclear behavioral intentions, attitude, trust, environmental beliefs, and values. Environment and Behavior, 45(6), 782-798.

Rayner, S. (2010). Trust and the transformation of energy systems. Energy Policy. 38, $2617-2623$

Schultz, W P. (2001). The structure of environmental concern: concern for self, other people, and the biosphere. Journal of Environmental Psychology, 21(4), 327-339. doi: 10.1006/jevp.2001.0227 
Semenza, J. C., Wilson, D. J., Parra, J., Bontempo, B. D., Hart, M., Sailor, D. J., \& George, L. A. (2008). Public perception and behavior change in relationship to hot weather and air pollution. Environmental Research, 107(3), 401-411.

Smith, W. S., Schueneman, J. J., \& Zeidberg, L. D. (1964). Public reaction to air pollution in Nashville, Tennessee. Journal of the Air Pollution Control Association, 14(10), 418-423.

Stoutenborough, J., Kirkpatrick, K., Field, M., \& Vedlitz, A. (2015). What butterfly effect? The contextual differences in public perceptions of the health risk posed by climate change. Climate, 3(3), 668-688.

Suldovsky, B., McGreavy, B., \& Lindenfeld, L. (2018). Evaluating Epistemic Commitments and Science Communication Practice in Transdisciplinary Research. Science Communication, 40(4), 499-523. doi: $10.1177 / 1075547018786566$

U.S. Census Bureau QuickFacts: Portland city, Oregon. (n.d.). Retrieved December 1, 2020, from https://www.census.gov/quickfacts/portlandcityoregon

Västfjäll, D., Peters, E., \& Slovic, P. (2014). The affect heuristic, mortality salience, and risk: Domain-specific effects of a natural disaster on risk-benefit perception. Scandinavian Journal of Psychology, 55(6), 527-532.

Vírseda, S., Restrepo, M. A., Arranz, E., Magán-Tapia, P., Fernández-Ruiz, M., Gómez de la Cámara, A., ... López-Medrano, F. (2010). Seasonal and pandemic A (H1N1) 2009 influenza vaccination coverage and attitudes among health-care workers in a Spanish university hospital. Vaccine, 28, 4751-4757. 
Von Gottberg, C., Krumm, S., Porzsolt, F., \& Kilian, R. (2016). The analysis of factors affecting municipal employees' willingness to report to work during an influenza pandemic by means of the extended parallel process model (EPPM). BMC Public Health, 16(27), 26

Wakefield, S., Elliott, S., Cole, D., \& Eyles, J. (2001). Environmental risk and (re)action: Air quality, health, and civic involvement in an urban industrial neighborhood. Health and Place, 7(3), 163-177.

Warshaw, K. (2018, June 3). The Survival Rule of Threes: Water. Retrieved from https://vlesdesigns.com/blogs/facts/the-survival-rule-of-threes-water

Weinhold, B. (2002). U.S. air only fair. Environmental Health Perspectives, 110(8), 452. doi: 10.1289/ehp.110-a452

Witte, K. (1992). Putting the fear back into fear appeals: The extended parallel process model. Communication Monographs, 59(4), 329-349.

Witte, K. (1994). Fear control and danger control: A test of the extended parallel process model (EPPM). Communications Monographs, 61(2), 113-134.

Witte, K., \& Allen, M. (2000). A meta-analysis of fear appeals: Implications for effective public health campaigns. Health Education \& Behavior, 27(5), 591-615.

Witte, K., Cameron, K. A., McKeon, J. K., \& Berkowitz, J. M. (1996). Predicting risk behaviors: Development and validation of a diagnostic scale. Journal of Health Communication, 1, 317-341. doi: 10.1080/108107396127988

Xiao, C. (2013). Public Attitudes Toward Science and Technology and Concern for the Environment: Testing a Model of Indirect Feedback Effects. Environment and Behavior, 45(1), 113-137. 
Xue, W., Hine, D. W., Marks, A. D., Phillips, W. J., Nunn, P., \& Zhao, S. (2016).

Combining threat and efficacy messaging to increase public engagement with climate change in Beijing, China. Climatic Change, 137(1-2), 43-55.

Yang, Z. J., Kahlor, L., \& Li, H. (2014). A United States-China comparison of risk information-seeking intentions. Communication Research, 41(7), 935-960.

York, R., \& Clark, B. (2010). Critical Materialism: Science, Technology, and Environmental Sustainability*. Sociological Inquiry, 80(3), 475-499.

Zeidler, D. L. (1984). Moral issues and social policy in science education: Closing the literacy gap. Science Education, 68(4), 411-419 


\section{Appendix A - Survey Protocol}

\section{Confidence in Science \& Technology}

Please indicate how much you agree or disagree with the following statements about science and technology.

\begin{tabular}{l|c|c|c} 
Strongly & Disagree & $\begin{array}{c}\text { Neither Disagree nor } \\
\text { Disagree }\end{array}$ & Agree
\end{tabular}$\quad \begin{gathered}\text { Strongly } \\
\text { Agree }\end{gathered}$

1. Most environmental problems can be solved by applying more and better technology.

2. Science and technology will eventually solve our problems with pollution, overpopulation, and diminishing resources.

3. Science and technology do as much environmental harm as good.

4. Modern science will NOT be able to solve our environmental problems

5. We cannot keep counting on science and technology to solve our environmental problems.

6. Humans will eventually learn how to solve all environmental problems.

7. The belief that advances in science and technology can solve our environmental problems is completely wrong and misguided.

8. Humans will eventually learn enough about how nature works to be able to control it.

9. Science and technology cannot solve the grave threats to our environment.

10. Modern science will solve our environmental problems.

\section{Extended Parallel Process Model}

Please indicate how much you agree or disagree with the following statements about air pollution.

\begin{tabular}{l|l|c|c|c|c}
$\begin{array}{l}\text { Strongly } \\
\text { Disagree }\end{array}$ & Disagree & $\begin{array}{c}\text { Neither Disagree } \\
\text { nor Agree }\end{array}$ & Agree & $\begin{array}{c}\text { Strongly } \\
\text { Agree }\end{array}$ & $\begin{array}{c}\text { I don't } \\
\text { know }\end{array}$
\end{tabular}

\section{Severity}

1. I believe that air pollution in my neighborhood is severe.

2. I believe that air pollution in my neighborhood is serious.

3. I believe that air pollution in my neighborhood is significant. 


\section{Susceptibility}

1. I am at risk of suffering from air pollution.

2. It is likely that I will suffer from air pollution

3. It is likely that I will suffer health problems because of air pollution.

\section{Self-efficacy}

1. I feel confident that I can protect myself from air pollution.

2. Protecting myself from air pollution is easy to do.

3. Protecting myself from air pollution is convenient.

\section{$\underline{\text { Demographics }}$}

Finally, we want to know a little bit more about you. Your individual information will not be shared with or reported to anyone outside of the research team, and will never be used to identify you in any way.

AGE: What is your year of birth? [drop-down menu]

SEX: What is your biological sex?

1. Male

2. Female

3. Intersex

RACE: What is your race? (Select all that apply)

1. White

2. Black or African American

3. American Indian or Alaska native

4. Asian

5. Native Hawaiian or pacific islander

6. Hispanic or Latino

7. Other

EDUCATION: What is the highest level of school you have completed or the highest degree you have received?

1. Less than high school

2. High school graduate

3. Some college

4. Associate degree (2-year)

5. Bachelor's degree (4-year)

6. Master's degree

7. Professional degree (JD, MD)

Doctoral degree 
INCOME: What was your entire household income last year before taxes?

1. Less than $\$ 10,000$

2. $\$ 10,000$ to $\$ 19,999$

3. $\$ 20,000$ to $\$ 29,999$

4. $\$ 30,000$ to $\$ 39,999$

5. $\$ 40,000$ to $\$ 49,999$

6. $\$ 50,000$ to $\$ 74,999$

7. $\$ 75,000$ to $\$ 99,999$

8. $\$ 100,000$ or more 